\title{
Improved Cryptosporidium case findings using immunofluorescent microscopy on concentrated stool
}

\author{
Cox, D., and *Robberts, F. J. L. \\ Division of Medical Microbiology, University of Cape Town, 1 Anzio Road, Observatory, 7925, South Africa \\ *Correspondence to: Irobberts@gmail.com; +27 645256360; https://orcid.org/0000-0003-4397-4852
}

\begin{abstract}
:
Background: Diarrhoea is a major cause of morbidity in Cape Town, South Africa, and mortality is attributed to a failure to recognize the severity of the condition. Cryptosporidium and Giardia are increasingly recognized as important causes of diarrhoea in Africa however, suboptimal diagnostic techniques may lead to underappreciation of their significance. Our objectives are to compare the diagnostic yield of direct immunofluorescent antigen (DFA) microscopy on concentrated stool samples for Cryptosporidium and Giardia, with the current approach of wet mount microscopy for Giardia and auramine fluorescent stain for Cryptosporidium on unconcentrated stool. Methodology: Stool specimens $(n=104)$ received at our hospital laboratory for routine microbiological investigations were used for the study. Direct wet-mount auramine-phenol fluorescent microscopy (auramine) detection of Cryptosporidium oocysts and wet mount iodine microscopy for Giardia detection, were performed on unconcentrated stool samples, while DFA stain for simultaneous detection of Cryptosporidium and Giardia was performed on sodium-acetate formalin concentrated stool samples. The diagnostic yields of the tests were compared using the MEDCALC ${ }^{\circledR}$ version 18.0

Results: Of the 104 stool specimens received for microbiological analysis, only 66 (63.5\%) had specific Cryptosporidium requests while $38(36.5 \%)$ had no Cryptosporidium specific requests. Of the 66 specimens, 9 $(13.6 \%)$ were positive for Cryptosporidium oocysts with DFA while only 1 (1.5\%) was positive with auramine staining $(p=0.013)$. The one auramine-positive specimen was also positive by DFA. Auramine stain microscopy gave a sensitivity of $11.1 \%(95 \% \mathrm{CI}: 0.28-48.25 \%)$ and specificity of $100 \%(95 \% \mathrm{CI}: 93.7 \%-100 \%)$ when compared to DFA. Of the 38 stool specimens without specific Cryptosporidium request, DFA yielded 5 (13.2\%) additional positive results. Taken together, Cryptosporidium was detected in 14/104 (13.5\%; 95\%CI: 8.36$21.7 \%)$ specimens and only 1 of $14(7.1 \%)$ specimens with the current routine laboratory testing approach. Giardia was detected by DFA in 3/104 (0.9\%) specimens, while direct iodine wet mount microscopy did not yield any positive results (0\%). All 3 Giardia-positive specimens had Cryptosporidium oocysts detected by DFA. Conclusion: These data suggest that a large proportion of Cryptosporidium cases remain undetected by the laboratory due to suboptimal testing methods, and failure by clinicians to specifically request for Cryptosporidium detection. There is need to periodically assess the effectiveness of diagnostic microbiology laboratory approaches to diarrhoea, and access to improved diagnostic laboratory techniques will contribute to more accurate differential diagnosis and a broadened understanding of local aetiology of diarrhoea diseases in Africa.
\end{abstract}

Keywords: Cryptosporidium, Giardia, diarrhoea, stool concentration, DFA, microscopy

Copyright 2021 AJCEM Open Access. This article is licensed and distributed under the terms of the Creative Commons Attrition 4.0 International License $<$ rel="license" href="http://creativecommons.org/licenses/by/4.0/", which permits unrestricted use, distribution and reproduction in any medium, provided credit is given to the original author(s) and the source. Editor-in-Chief: Prof. S. S. Taiwo

\section{Amélioration des découvertes de cas de Cryptosporidium à l'aide de la microscopie immunofluorescente sur des selles concentrées}

\author{
Cox, D., et *Robberts, F. J. L.
}

Division de microbiologie médicale, Université de Cape Town, 1 Anzio Road, Observatory, 7925, Afrique du Sud *Correspondance à: Irobberts@gmail.com; +27 645256360; https://orcid.org/0000-0003-4397-4852

\begin{abstract}
Abstrait:
Contexte: La diarrhée est une cause majeure de morbidité au Cap, en Afrique du Sud, et la mortalité est attribuée à l'incapacité de reconnaître la gravité de la maladie. Cryptosporidium et Giardia sont de plus en plus reconnus
\end{abstract}


comme des causes importantes de diarrhée en Afrique, cependant, des techniques de diagnostic sous-optimales peuvent conduire à une sous-estimation de leur importance. Nos objectifs sont de comparer le rendement diagnostique de la microscopie à antigène immunofluorescent direct (DFA) sur des échantillons de selles concentrées pour Cryptosporidium et Giardia, avec l'approche actuelle de la microscopie à montage humide pour Giardia et la coloration fluorescente auramine pour Cryptosporidium sur des selles non concentrées. Méthodologie: Des échantillons de selles $(n=104)$ reçus au laboratoire de notre hôpital pour des examens microbiologiques de routine ont été utilisés pour l'étude. La détection directe par microscopie fluorescente auramine-phénol à montage humide (auramine) des oocystes de Cryptosporidium et la microscopie à l'iode à montage humide pour la détection de Giardia, ont été effectuées sur des échantillons de selles non concentrées, tandis que la coloration DFA pour la détection simultanée de Cryptosporidium et de Giardia a été réalisée sur de l'acétate de sodium formaline concentré échantillons de selles. Les rendements diagnostiques des tests ont été

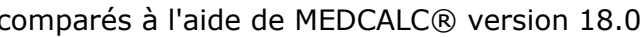

Résultats: Sur les 104 échantillons de selles reçus pour l'analyse microbiologique, seuls $66(63,5 \%)$ avaient des demandes spécifiques de Cryptosporidium tandis que 38 (36,5\%) n'avaient pas de demandes spécifiques de Cryptosporidium. Sur les 66 échantillons, $9(13,6 \%)$ étaient positifs pour les oocystes de Cryptosporidium avec DFA tandis que seulement $1(1,5 \%)$ était positif avec coloration à l'auramine $(p=0,013)$. Le seul échantillon positif à l'auramine était également positif au DFA. La microscopie à l'auramine a donné une sensibilité de $11,1 \%$ (IC 95\%: 0,28-48,25\%) et une spécificité de 100\% (IC 95\%: 93,7\% -100\%) par rapport au DFA. Sur les 38 échantillons de selles sans demande spécifique de Cryptosporidium, le DFA a donné $5(13,2 \%)$ résultats positifs supplémentaires. Pris ensemble, Cryptosporidium a été détecté dans 14/104 (13,5\%; IC à 95\%: 8,36-21,7\%) et seulement 1 des 14 échantillons $(7,1 \%)$ avec l'approche actuelle des tests de routine en laboratoire. Giardia a été détecté par DFA dans 3/104 (0,9\%) échantillons, tandis que la microscopie directe à l'iode sur monture humide n'a donné aucun résultat positif $(0 \%)$. Les 3 échantillons positifs à Giardia avaient des oocystes de Cryptosporidium détectés par DFA.

Conclusion: Ces données suggèrent qu'une grande proportion des cas de Cryptosporidium ne sont pas détectés par le laboratoire en raison de méthodes de test sous-optimales et de l'échec des cliniciens à demander spécifiquement la détection de Cryptosporidium. Il est nécessaire d'évaluer périodiquement l'efficacité des approches de laboratoire de microbiologie diagnostique pour la diarrhée, et l'accès à des techniques de laboratoire de diagnostic améliorées contribuera à un diagnostic différentiel plus précis et à une compréhension élargie de l'étiologie locale des maladies diarrhéiques en Afrique.

Mots clés: Cryptosporidium, Giardia, diarrhée, concentration des selles, DFA, microscopie

\section{Introduction:}

Diarrheal disease in developing countries account for up to $21 \%$ of deaths in children less than 5 years. Approximately $78 \%$ of these occur in Africa and South East Asia (1). In South Africa, diarrhea is the third leading cause of infant mortality $(16 \%)$, trailing behind deaths in the neonatal period $(27.5 \%)$ and HIV/AIDS (19.5\%) (2). In the Western Cape Province, diarrhoea is the third leading cause of under-five mortality (11\%); almost half $(42.9 \%)$ of child diarrheal deaths in the Cape Town metro sub-district occur at home (3). Among those who seek primary healthcare, some are locally managed, while others are referred to tertiary care; a main contributing factor for diarrheal death among those referred to tertiary care in South Africa is a failure to correctly assess the severity of the child's condition (4).

The enteric coccidian parasites, Cryptosporidium parvum and Cryptosporidium hominis, and the protozoan parasite, Giardia duodenalis are important causes of diarrhea globally. Cryptosporidium is increasingly recognized as a leading cause of moderate-tosevere diarrhea in both immunocompetent and immunosuppressed subjects (5). The Global Enteric Multicenter Study (GEMS) showed that Cryptosporidium is second only to Rotavirus as a contributor to moderate-tosevere diarrhea in sub-Saharan Africa (6). Cryptosporidium is transmitted via contami- nated food, water, and from person-to-person particularly where suboptimal sanitation and limited access to safe drinking water prevail. Similarly transmitted, Giardia is a major cause of intestinal disease globally, with a higher prevalence in Africa (7). Chronic infection can lead to weight loss and malabsorption and is associated with stunting, wasting and cognitive impairment in children (8).

Clinical management guidelines highlight the need, importance and calls for improved effectiveness of test and treat approaches to diarrhoea $(1,9,10)$. Availability of accurate diagnostic laboratory tests are neglected, and evaluation and improvements are much needed $(1,11,12)$. Our objectives were to employ stool concentration and immunofluorescent stain for the detection of Cryptosporidium and Giardia on all stool samples received for microbiological investigations at an academic pathology laboratory in Cape Town, South Africa, and compare findings to those obtained with the current methods employed by the laboratory.

\section{Materials and method:}

\section{Study setting and specimens}

Unpreserved diarrheal stool specimens $(n=104)$ received for routine microbiological investigations at the National Health Laboratory Services (NHLS), University of Cape Town Department of Pathology at Groote Schuur Hospital, were collected from 12 June through 
6 August 2014. The NHLS laboratory receives specimens for testing from hospitalized patients as well as specimens from secondary hospitals and clinics in the Southern Cape Town area, including the Red Cross Children's Hospital, a national paediatric referral hospital. Current routine laboratory investigations include direct wet mount with iodine microscopic analysis of stool specimens. Auraminephenol fluorescent microscopy is performed when Cryptosporidium or Isospora testing is specifically requested. The remains of stool specimens after routine testing were collected by the researchers who were blinded to testing results.

\section{Ethical approval}

This study was approved by the Human Research Ethics Committee, Faculty of Health Sciences, University of Cape Town (Ref: 240/2014).

\section{Microscopic examination of specimens}

A grape sized amount, or a $5 \mathrm{ml}$ aliquot of liquid stool, was added to $40 \mathrm{ml}$ of sodium acetate-acetic acid-formalin (SAF) in a $50 \mathrm{ml}$ conical centrifuge tube and mixed by inversion until homogenous mixture was attained. The preserved stool samples were concentrated using a commercial kit (Para-Pak $®$ Spin-Con $®$ Stool Concentration System, Meridian Bioscience, Cincinnati, $\mathrm{OH}$ ) according to the manufacturer's package insert (13). A direct immunofluorescent assay (DFA) (Merifluor ${ }^{\circledR}$ Cryptosporidium/Giardia Direct Immunofluorescent Assay, Meridian Bioscience) was performed according to the manufacturer's instructions (14).

Each slide was viewed under an LED fluorescent microscope with an excitation wavelength of $490-500 \mathrm{~nm}$ under the $40 \mathrm{x}$ objective lens with a calibrated eyepiece $10 x$ ocular lens with micrometer (total magnification 400x) for specific size measurements. Samples were screened for Cryptosporidium oocysts and Giardia cysts based on colour, shape and size. Both internal kit controls and external control slides were included in each staining process. External control slides comprising stool specimens previously shown to contain Cryptosporidium oocysts and Giardia cysts were kindly provided by the Centre for Opportunistic, Hospital and Tropical Diseases, National Institute for Communicable Diseases, South Africa.

\section{Statistical analysis}

Statistical calculations for diagnostic test evaluation were performed using MEDCALC $^{\circledR}$ version 18 (www.medcalc.org) and McNemar's test for significance was applied. P value less than 0.05 was considered to be statistically significant.

\section{Results:}

Of the 104 stool specimens received for microbiological analysis, only 66 (63.5\%) had specific Cryptosporidium request. Of the 66 stool specimens tested for Cryptosporidium oocysts using both the routine direct wetmount auramine-phenol fluorescent microscopy and the DFA microscopy on concentrated specimen, only $1(1.5 \%)$ specimen yielded a positive auramine finding compared to $9(13.6 \%)$ with DFA $(p=0.013)$. The one auramine-positive specimen was also positive by DFA. Direct wet-mount auramine microscopy yielded a sensitivity of $11.1 \%$ (95\% CI: $0.28 \%-48.25 \%)$ and specificity of $100 \%$ (95\% CI: $93.7 \%-100 \%)$ when compared to DFA.

Of additional 38 stool specimens received for microbiological analysis without a specific request for Cryptosporidium testing (no direct auramine), DFA yielded 5 (13.2\%) additional positive results. Taken together, Cryptosporidium was detected in $14 / 104(13.5 \%$; 95\%CI: $8.36-21.7 \%$ ) specimens, and only 1 of $14(7.1 \%)$ cases was successfully detected with the current routine laboratory testing approach. Giardia was detected by DFA in $3 / 104(0.9 \%)$ specimens, while direct iodine wet mount microscopy did not yield any positive results $(0 \%)$. All 3 Giardia-positive specimens had Cryptosporidium oocysts detected in them by DFA.

\section{Discussion:}

Case findings of Cryptosporidium in concentrated stool combined with DFA microscopy was significantly higher $(13.6 \%)$ than those obtained using unconcentrated stool microscopy with auramine (1.5\%). Similarly, case findings of Giardia were enhanced with DFA on concentrated stool $(4.5 \%)$ compared to direct iodine microscopy $(0 \%)$. An additional 5 of 38 cases of Cryptosporidium were detected in stool without a request for Cryptosporidium investigation. These data suggest that a large proportion of Cryptosporidium cases remain undetected by the laboratory due to suboptimal testing methods used, as well as a failure by clinicians to specifically request testing for Cryptosporidium.

The Cryptosporidium prevalence of $13.5 \%(14 / 104)$ reported in this study is in line with findings elsewhere in South Africa. In the Northern metro district of Cape Town Nel et al., reported $10.4 \%$ of children under 5 years of age with diarrhoea yielded Cryptosporidium (15). In Limpopo province, Cryptosporidium was reported in $25.2 \%$ of hospital patients and $17.9 \%$ of diarrheal samples in school children (16). Our findings are consistent with the recognized laboratory standards 
recommending concentration of stool for recovery of intestinal parasites, and the improved sensitivity and specificity of DFA for the detection of Cryptosporidium $(17,18)$.

This study was limited to the months of June to August representing the winter/rain season in the Western Cape. The etiological causes of diarrhea may be affected by seasonality. However, Cryptosporidium is more commonly found in cases of diarrhoea than is suspected. Relying on unconcentrated stool for detection of Cryptosporidium is therefore suboptimal. DFA detection on concentrated stool improves case findings. These findings suggest the need to periodically assess the effectiveness of the microbiological diagnostic approach into the causes of diarrhoea.

\section{Authors contributions:}

FJLR conceptualized the study, obtained funding, and provided supervision. DC performed the investigation and curated the data. Both authors contributed to the analysis of data and writing of the manuscript.

\section{Acknowledgements:}

The authors acknowledge with thanks Angela Klein (National Health Laboratory Services) for assisting with specimen coordination, Prof. John Frean and Bhavani Poonsamy (Centre for Opportunistic, Hospital and Tropical Diseases, National Institute for Communicable Diseases) for providing positive external control materials, and Prof. William Horsnell (University of Cape Town) for support.

\section{Conflicts of interest:}

No conflicts of interest are declared.

\section{Funding information:}

This work was supported by a grant from the Centre for Opportunistic, Hospital and Tropical Infections, National Institute of Communicable Diseases, South Africa.

\section{References:}

1. World Health Organization. WHO recommendations on the management of diarrhoea and pneumonia in HIV-infected infants and children: Integrated Management of Childhood Illness (IMCI) Geneva, World Health Organisation, 2010.

2. Msemburi, W., Pillay-van Wyk, V., Dorrington, R. E., et al. Second national burden of disease study for South Africa: Cause-of-death profile for South Africa, 1997-2012. Cape Town: South African Medical Research Council, 2016

3. Groenewald, P. Msemburi, W. Morden, E., et al. Western Cape Mortality Profile 2011. South African Medical Research Council. Cape Town; 2014.
4. National Department of Health. Second triennial report of the committee on morbidity and mortality in Children Under 5 Years (CoMMiC) 2011. Pretoria; 2014

5. Squire, S. A., and Ryan, U. Cryptosporidium and Giardia in Africa: current and future challenges. Parasites \& Vectors 2017; 10: 195.

6. Kotloff, K. L., Nataro, J. P., Blackwelder, W. C., et al. Burden and aetiology of diarrhoeal disease in infants and young children in developing countries (the Global Enteric Multicenter Study, GEMS): a prospective, case-control study. Lancet 2013; 382: 209-222.

7. Feng, Y., and Xiao, L. Zoonotic potential and molecular epidemiology of Giardia species and giardiasis. Clin Microbiol Rev. 2011; 24: 110140.

8. Berkman, D. S., Lescano, A. G., Gilman, R. H. Lopez, S. L., and Black, M. M. Effects of stunting, diarrhoeal disease, and parasitic infection during infancy on cognition in late childhood: a followup study. Lancet. 2002; 359: 564-571.

9. Juckett, G., and Trivedi, R. Evaluation of chronic diarrhoea. Am Fam Physician. 2011; 84: 10.

10. Schiller, L. R. Chronic diarrhoea. Gastroenterol. 2004; 127: 287-293.

11. Abba, K., Garner, P., Haart, C. A., and Sinfiled, R. Antimicrobial drugs for persistent diarrhoea of unknown or non-specific cause in children under six in low-and-middle-income countries: systematic review of randomized controlled trials. BMC Infect Dis. 2009; 9: 24

12. Aranda, J. V., Lukacik, M., and Thomas, R. L. A meta-analysis of the effects of oral zinc in the treatment of acute and persistent diarrhea. Pediatr. 2007; 121: 326.

13. Para-Pak $\AA$ SpinCon $\AA$ Stool Concentration System, package insert. Meridian Biosciences, Inc. Cincinnati, OH. 2001.

14. MerIFluor $\circledR$ Cryptosporidium/Giardia, package insert. Meridian Biosciences, Inc. Cincinnati, $\mathrm{OH}$. 2013.

15. Nel, E. D., Rabie, H., Goodway, J., and Cotton, M. F. A retrospective study of Cryptosporidial d diarrhea in a region with high HIV prevalence. J Trop Pediatr. 2011; 57: 289-292.

16. Samie, A., Guerrant, R. L., Barrett, L., Bessong, P. O., Igumbor, E. O., and Obi, C. L. Prevalence of intestinal parasitic and bacterial pathogens in diarrhoeal and non-diarrhoeal human stools from Vhembe District, South Africa. J Hith Population Nutr. 2009; 27: 739-745.

17. Clinical and Laboratory Standards Institute (CLSI). Procedures for the recovery and identification of parasites from the intestinal tract; Approved Guideline - Second Edition. CLSI document M28-A2. Clinical and Laboratory Standards Institute, Wayne, PA, 2005.

18. Stibbs, H. H., and Ongerth, J. E. Immunofluorescence detection of Cryptosporidium oocyst in fecal smears. J Clin Microbiol. 1986; 24: 517521. 